\title{
The Role of Age on Effectiveness of Active Repositioning Therapy in Positional Skull Deformities
}

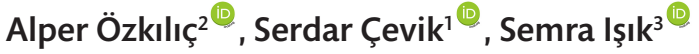 \\ ${ }^{1}$ Memorial Şişli Hospital, Department of Neurosurgery, İstanbul, Turkey \\ ${ }^{2}$ Biruni University, Department of Pediatrics, İstanbul, Turkey \\ ${ }^{3}$ Başkent University Istanbul Hospital, Department of Neurosurgery, İstanbul, Turkey \\ Address for Correspondence: Serdar Çevik, E-mail: dr.serdarcevik@gmail.com \\ Received: 2708 2019. Accepted: 07112019 . Available Online Date: 27012020 \\ CCopyright 2019 by Dokuz Eylül University, Institute of Health Sciences - Available online at www.jbachs.org \\ Cite this article as: Özkılıç A, Çevik S, Işık S. The Role of Age on Effectiveness of Active Repositioning Therapy in Positional Skull Deformities J Basic Clin Health Sci 2020; 1:33-37.
}

\begin{abstract}
Purpose: Non-synostotic positional deformities are currently diagnosed in nearly half of the newborns, however not any evidence-based guidelines are available for management. The aim of this study is to assess the effect of active repositioning treatment at infants with positional skull deformities.

Method: A retrospective data of 158 infants treated with active repositioning as a conservative treatment for at least 2 months were analyzed in this study. Anthropometric 3D scanner measurements of pre-and post-treatment diagonal difference, cranial vault asymmetry index, cranial ratio were evaluated for each patient. Infants were separated to 4 different groups according to their morphologic deformation types as plagiocephaly, brachycephaly, scaphocephaly and combined (brachycephaly+plagiocephaly), and 2 groups according to age at onset of treatment.

Results: In combined group, pre-treatment mean diagonal difference and cranial vault asymmetry index values decreased from $9.38 \mathrm{~mm}$ and $6.9 \%$ to $6.94 \mathrm{~mm}$ and $4.9 \%$ respectively. In plagiocephaly group, mean pre-treatment results changed from $10.32 \mathrm{~mm}$ and $7.5 \%$ to $7.83 \mathrm{~mm}$ and $5.5 \%$ respectively after treatment. All these changes were statistically significant. Effectiveness of timing of repositioning treatment on different positional skull deformities was analyzed and outcome was found significantly improved when the active repositioning treatment was started before 4 months of age.

Conclusion: Improvement rates of the asymmetry decrease with age due to decreasing skull enlargement rate. Early diagnosis, especially before 4 months of age, more parental education, and close follow-up are important for babies with this condition who may benefit just from repositioning treatment.
\end{abstract}

Key Words: Positional plagiocephaly, Positional brachycephaly, Cranial deformation, conservative therapy, active repositioning therapy

\section{INTRODUCTION}

Neonatal skull is soft and moldable in the natal and newborn periods due to the rapidly growing brain tissue. Skull deformities may be classified as; pathologic type, craniosynostosis, secondary to abnormal suture development; or deformational/positional type secondary to external forces acting upon cranium. Craniosynostosis usually requires surgical intervention, however with early diagnosis, positional skull deformities may be treated with active repositioning, physical therapy and helmet therapy in infants (1-3).

American Pediatric Academy (APA) has started a campaign and suggested that the babies should be at supine position in bed to decrease sudden infant death. (4) Soon after acceptance of supine position in bed campaign in almost all countries, 50\% decrease in sudden infant death syndrome was recorded. (5) However, Argenta et. al in 1996 reported up to $600 \%$ increase in the prevalence of cranial asymmetries. Thus, a consensus has been made about the relation between deformational plagiocephaly and supine sleeping position. $(6,7)$

Nowadays, skull deformities are diagnosed in $45 \%$ of infants, with most common diagnoses being plagiocephaly, brachycephaly and scaphocephaly. Symptoms may be observed initially between 4th and 8th weeks of life. (8-11). Positional plagiocephaly can be recognized as unilateral parieto-occipital flattening with ipsilateral frontal bossing and anterior shift of the ipsilateral ear that results in a parallelogram deformity of the head. Central bi-occipital flattening with an anterior to posterior shortening and medial to 
lateral widening of the head is the characteristics of deformational brachycephaly, therefore it is also known as 'short head' syndrome (11). Scaphocephaly, 'narrow head' , is characterized by anteriorposterior elongation and bi-parietal shortening of the skull (12, 13). Besides the cosmetic problems, it is suggested that positional deformities may constitute a risk for temporo-mandibular joint problems, motor skill deficiencies, sleep apnea syndrome, visual field defects, ear infections, difficulties at cognitive functions and academic degrees (14-18).

The first postnatal 4 months are critical for the development of positional skull deformities (PSD), and a peak is observed at the deformation level by the end of 4th month (19). Therefore, in 2008 American Pediatric Academy (APA) proposed that, infants should be positioned in a facedown position 2-3 times for 3-5 minutes, under surveillance, during their awake times to prevent cranial asymmetry, and that this duration should be increased as the child grows older (20). Since the infant skull is easier to mold, early infancy is the most favorable time to prevent PSD.

The aim of this study is to investigate the effects of early conservative treatment in PSD patients on improvement of cranial asymmetry rates.

\section{MATERIALS AND METHODS}

A retrospective analyzes of all infants admitted to our outpatient clinics due to skull shape deformities between 2014 and 2018 were performed. The infants who received positional treatment for at least 2 months were determined and included to the study. Parameters including gender, delivery method (vaginal delivery vs caesarian section), gestational age at birth (premature/mature), twin status, age at diagnosis, onset of treatment, treatment duration (days), anthropometric measures of pre-and posttreatment diagonal difference (DD), cranial vault asymmetry index (CVAI), cranial ratio (CR) were evaluated for each patient.
Cranial parameter analyze were made with SmartSoc and Omega Scanner 3D systems (Figure 1). The same instrument was used for all measurements of each individual infant throughout the study. Either of these two systems was used for each patient, they were never used together. The same technician performed the scanning and evaluated the cranial alignment for each infant.

Patients were disintegrated morphologically into 4 groups: Group I (plagiocephaly), infants whose cephalic index was between 78-89 and CVAI was greater than\% 3.5; Group II (brachycephaly), infants whose cephalic index was greater than 89 and CVAI was lesser than\% 3.5; Group III (scaphocephaly), infants with cephalic index lesser than 78; Group IV (combined: brachycephaly+plagiocephaly), infants whose cephalic index was greater than 89 and CVAI was greater\% 3.5. Infants were distributed into 2 groups according to age at diagnosis: Group A, infants aged below 4 months of age and Group B, infants aged 4 months and older.

Statistical analyses were performed using IBM ${ }^{\circledR}$ SPSS ${ }^{\circledR}$ Statistics (version 21.0). Student t-test or Mann Whitney $U$ test were used to compare variables between cohorts. $p<0.05$ was accepted as statistically significant.

\section{RESULTS}

A total of 158 infants were included in the study. Demographics and basic evaluations regarding perinatal and neonatal examinations are detailed in Table 1. A 3D scanner was used to analyze pretreatment and post-treatment anthropometric measurements of 93 boys (58.7\%) and 65 girls (41.3\%). Infants were diagnosed as follows: plagiocephaly in 78 (49.3\%) infants, combined (plagiocephaly+brachycephaly) in 57 (36.1\%), brachycephaly in $16(10.1 \%)$, and scaphocephaly in 7 (4.4\%) infants.

In Group I, mean pre-treatment DD results changed from 10.32 $\mathrm{mm}[ \pm 2.74$ (range 6-20)] to 7.83 [ $\pm 3.45 \mathrm{~mm}$ (range, 1-19)] after treatment. Pre-treatment CVAI values in this group changed from

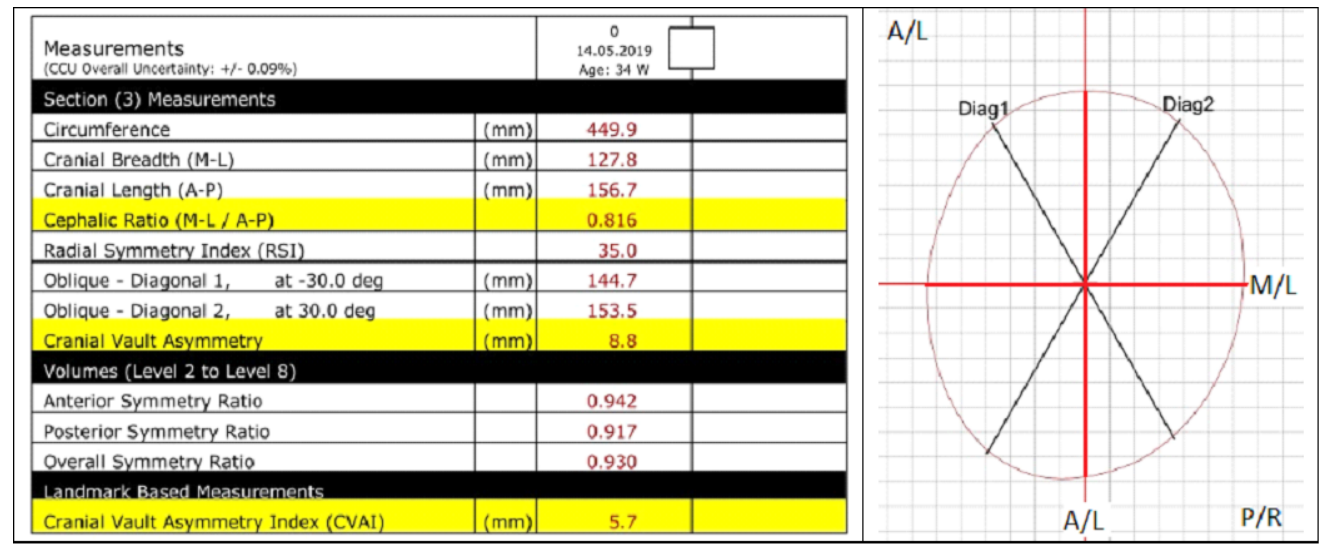

Figure 1. Diagonal diameters (Diag 1 and Diag 2) are measured in millimeters at either 30 degrees (whichever is greater) from the center of the nose to the outer edge of the eyebrow. Glabella and opisthocranion landmarks were used for circumferential measurements and cranial length, which is AP, and right and left ear lobe landmarks were used to measure cranial width, which is ML.

Diagonal Difference (DD)=Diagonal 1-Diagonal 2

Cephalic Ratio $(C R)=(M-L / A-P) \times 100$

Cranial Vault Asymmetry Index (CVAI)=(Diagonal 1 - Diagonal 2)/(Diagonal 1 or Diagonal 2) X100 
$7.5 \%[ \pm 1.98 \%$ (range $3.8-14.92)]$ to $5.5 \%[ \pm 2.45 \%(1.05-14.25)$ in the post-treatment period. Both these differences were statistically significant $\left(P_{D D}=0.0001\right.$ and $\left.P_{C V A l}=0.0001\right)$ (Table 2).

The mean pre-treatment and post-treatment values of Group II and Group III were evaluated and no statistically significant differences were found (Table 2).

In combined group, Group IV, pre-treatment mean DD values were found $9.38 \mathrm{~mm}[ \pm 2.67$ (range 5-14)], whereas post-treatment values decreased to $6.94 \mathrm{~mm}[ \pm 3$ (range 1-12). The pre-treatment

Table 1. Demographic characteristics of 158 infants Means \pm SDs or $n(\%)$

\begin{tabular}{lc}
\hline Gender & \\
Males & $93(58.7 \%)$ \\
Female & $65(41.3 \%)$ \\
Birth age (gestational week) & \\
Mature (born at $\geq 38)$ & $128(81 \%)$ \\
Premature (born at <38) & $30(19 \%)$ \\
Method of delivery & \\
Vaginal & $49(31 \%)$ \\
Caesarian-section & $109(69 \%)$ \\
Vacuum assisted delivery & $3(2 \%)$ \\
Presentation at delivery & \\
Occiput anterior & $99(63 \%)$ \\
Occiput posterior & $32(20 \%)$ \\
Breech & $27(17 \%)$ \\
Incubator follow up after delivery & $19(12 \%)$ \\
Maternal age (year) & $26.4 \pm 3.2$ \\
Primiparous mother & $37(23.4 \%)$ \\
Twin sibling & $25(15.8 \%)$ \\
\hline
\end{tabular}

CVAl values were recorded as 6.9\% $[ \pm 1.99 \%$ (range $3.56-11.37$ ) and post-treatment CVAI values were recorded as $4.9 \%[ \pm 2.0 .8 \%$ (range 0.5-9.08). All these changes were statistically significant $\left(P_{D D}=0.0001, P_{C V A l}=0.0001\right)$ (Table 2$)$.

In plagiocephaly deformation types, difference between pre-and post-treatment CVAI and DD levels were statistically significant in both groups of diagnostic age, Group A and Group B. However, in combined deformation types, the regression of CVAI and DD levels were not statistically significant for Group B infants (Table 3). In combined deformation types, absolute change in both DD and CVAI levels after treatment were significantly different at Group A compared to Group B infants (Table 4). [DD (-3.4 \pm 2.6 versus-1.25 $\pm 1.45, \mathrm{p}=0.001)$; CVAl $(-2.7 \pm 1.99$ versus-1.14 \pm 0.99 , $\mathrm{p}=0.0001$ )] (Table 4). In plagiocephaly group, although it is not statistically significant, the regression rates at mean DD and CVAI levels after treatment of age $<4$ months infants were better than the age $\geq 4$ months infants, $[(-3.03 \pm 2.61$ versus $-2.04 \pm 2.83$, $\mathrm{p}=0.209)$; CVAI $(-2.29 \pm 1.83$ versus $-1.73 \pm 1.7, \mathrm{p}=0.213)]$ (Table 4).

\section{DISCUSSION}

Our study analyses the impact of conventional treatment (repositioning) on the management of skull deformities. We found that when started at infants $<4$ months old they responded better to treatment compared to the infants $\geq 4$ months old. This was shown with statistically significant better reduction in DD and CVAl values after treatment in the former group. In general, our results indicate that the repositioning treatment efficacy is related to the age at onset of treatment, and the outcome is significantly improved when the treatment is started before 4 months of age.

Table 2. Pre-treatment and post-treatment values of plagiocephaly, brachycephaly, scaphocephaly and combined deformities

\begin{tabular}{|c|c|c|c|c|c|c|c|c|c|}
\hline & \multicolumn{2}{|c|}{ DD, mm } & \multirow[b]{2}{*}{$\mathbf{p}$} & \multicolumn{2}{|c|}{ CVAI, \% } & \multirow[b]{2}{*}{$\mathbf{p}$} & \multicolumn{2}{|c|}{$C R, \%$} & \multirow[b]{2}{*}{$\mathbf{p}$} \\
\hline & $\begin{array}{c}\text { onset of } \\
\text { treatment }\end{array}$ & $\begin{array}{l}\text { end of } \\
\text { treatment }\end{array}$ & & $\begin{array}{c}\text { onset of } \\
\text { treatment }\end{array}$ & $\begin{array}{c}\text { end of } \\
\text { treatment }\end{array}$ & & $\begin{array}{c}\text { onset of } \\
\text { treatment }\end{array}$ & $\begin{array}{c}\text { end of } \\
\text { treatment }\end{array}$ & \\
\hline Plagiocephaly & $10.32 \pm 2.74$ & $7.83 \pm 3.45$ & 0.001 & $7.5 \pm 1.98$ & $5.5 \pm 2.45$ & 0.001 & $83.8 \pm 3.02$ & $85.16 \pm 3.1$ & 0.006 \\
\hline Brachycephaly & $2.37 \pm 1.25$ & $2.62 \pm 1.66$ & 0.635 & $1.63 \pm 0.79$ & $1.86 \pm 1.32$ & 0.558 & $93.6 \pm 1.9$ & $92.3 \pm 3.1$ & 0.160 \\
\hline Scaphocephaly & $3.42 \pm 1.39$ & $2.42 \pm 1.71$ & 0.256 & $2.17 \pm 0.82$ & $1.79 \pm 1.11$ & 0.502 & $74.3 \pm 2$ & $76.6 \pm 3.5$ & 0.070 \\
\hline Combined & $9.38 \pm 2.67$ & $6.94 \pm 3$ & 0.001 & $6.9 \pm 1.99$ & $4.9 \pm 2.08$ & 0.001 & $92.3 \pm 2.33$ & $92.1 \pm 2.63$ & 0.680 \\
\hline
\end{tabular}

Combined, brachycephaly+plagiocephaly; CR, cranial ratio; CVAl, cranial vault asymmetry index; DD, diagonal difference; $p, p$-value.

Table 3. Difference between pre-and post-treatment CVAI and DD levels in groups of diagnostic age

\begin{tabular}{|c|c|c|c|c|c|c|}
\hline & \multicolumn{2}{|c|}{ DD, mm } & \multicolumn{4}{|c|}{ CVAI, \% } \\
\hline & onset of treatment & $\begin{array}{l}\text { end of } \\
\text { treatment }\end{array}$ & $\mathbf{p}$ & $\begin{array}{c}\text { onset of } \\
\text { treatment }\end{array}$ & $\begin{array}{l}\text { end of } \\
\text { treatment }\end{array}$ & $\mathbf{p}$ \\
\hline \multicolumn{7}{|c|}{ Plagiocephaly } \\
\hline$<4$ months & $10.67 \pm 2.51$ & $7.63 \pm 3.28$ & 0.0001 & $7.78 \pm 1.93$ & $5.49 \pm 2.31$ & 0.0001 \\
\hline$\geq 4$ months & $9.91 \pm 2.87$ & $7.87 \pm 3.83$ & 0.042 & $7.18 \pm 2.18$ & $5.44 \pm 2.72$ & 0.018 \\
\hline \multicolumn{7}{|l|}{ Combined } \\
\hline$<4$ months & $10 \pm 2.72$ & $6.63 \pm 3.14$ & 0.0001 & $7.44 \pm 2.03$ & $4.74 \pm 2.25$ & 0.0001 \\
\hline$\geq 4$ months & $8.54 \pm 2.39$ & $6.94 \pm 3$ & 0.104 & $6.19 \pm 1.72$ & $5.05 \pm 1.86$ & 0.099 \\
\hline \multicolumn{7}{|l|}{ All patients } \\
\hline$<4$ months & $10.41 \pm 2.6$ & $7.24 \pm 3.24$ & 0.0001 & $7.65 \pm 1.97$ & $5.20 \pm 2.3$ & 0.0001 \\
\hline$\geq 4$ months & $9.22 \pm 2.7$ & $7.58 \pm 3.34$ & 0.009 & $6.68 \pm 2$ & $5.25 \pm 2.31$ & 0.001 \\
\hline
\end{tabular}

Combined, brachycephaly+plagiocephaly; CVAI, cranial vault asymmetry index; DD, diagonal difference; $p, p$-value. 


\begin{tabular}{|c|c|c|c|c|c|c|c|c|}
\hline \multicolumn{3}{|c|}{ Combined } & \multicolumn{3}{|c|}{ Plagiocephaly } & \multicolumn{2}{|c|}{ Total } & \multirow{2}{*}{$\frac{\mathbf{p}}{0.524}$} \\
\hline $\begin{array}{c}<4 \text { months } \\
66.2 \pm 7.4\end{array}$ & \begin{tabular}{|c|}
$\geq 4$ months \\
$68.5 \pm 14.2$
\end{tabular} & $\begin{array}{c}\mathbf{p} \\
0.477\end{array}$ & $\begin{array}{c}<4 \text { months } \\
65.2 \pm 8.2\end{array}$ & \multicolumn{2}{|c|}{$\geq 4$ months $p$} & $\begin{array}{l}<4 \text { months } \\
66.7 \pm 11.2\end{array}$ & $\begin{array}{c}\geq 4 \text { months } \\
65.5 \pm 7.9\end{array}$ & \\
\hline & & & & & & & & \\
\hline (-) $2.7 \pm 1.99$ & (-) $1.14 \pm 0.99$ & 0.0001 & $(-) 2.29 \pm 1.83$ & $(-) 1.73 \pm 1.7$ & 0.213 & (-) $2.4 \pm 1.89$ & $(-) 1.4 \pm 1.41$ & 0.0006 \\
\hline
\end{tabular}

Combined; brachycephaly+plagiocephaly, CVAl; cranial vault asymmetry index, DD; diagonal difference, $\mathrm{p}$; $\mathrm{p}$-value

The main purpose of our study is to analyze the efficacy of early repositioning treatment using photogrammetric methods. In this study of 158 infants, we observed that, in the group of infants diagnosed and treated before 4 months of age, mean pre-treatment DD of $10.4 \mathrm{~mm}$ and CVAI of $7.65 \%$ improved to mean DD of $7.24 \mathrm{~mm}$ and CVAI of $5.2 \%$ after treatment. For the group of infants diagnosed and treated after the age of 4 months, mean pre-treatment DD of 9.2 $\mathrm{mm}$ and CVAl of $6.68 \%$ improved to mean DD of $7.58 \mathrm{~mm}$ and CVAI of $5.25 \%$ at the post-treatment period. Comparison of improvements at DD and CVAl measurements in both groups revealed that the significance of improvement was much more prominent in the treatment Group A, which are similar to those previously reported in literature. Shweikeh et al. reviewed 15 articles in literature and investigated the efficacy of current skull deformity management guidelines. They concluded that parents should be informed as early as possible about positional skull deformity (PSD) and that the education by means of close surveillance is the center of prevention and management of this disorder (21).

Craniofacial measurements are quite important in the diagnosis and evaluation of these patients (22). Previous studies investigated various techniques and skull shape measurements for the diagnosis and follow-up of PSD, however there is no consensus on a practical clinical method to measure the intensity and the change of deformity (23). Radiologic diagnostic techniques are barely helpful in these patients, and although plain radiographs and computerized tomography (CT) scans were performed in the past for these patients, these are not recommended as routine diagnostic tools for patient evaluation. The CT scans are not preferred for long-term follow-up in infants and children since the patient is exposed to high dose radiation, and it requires sedation to immobilize the patient to obtain optimum images. However, CT may be preferred in the differential diagnosis between deformational disorders and craniosynostosis, if there is suspicion after clinical evaluation (24). Nevertheless, 3D measurement devices provide non-invasive, effective, reliable and low-cost evaluation of skull asymmetries. Furthermore, this technique is compatible with the gold standard 3D CT technique in the diagnosis and follow-up, and may even provide more detailed and accurate shape information. (25).

Neglected cranial deformations may lead to negative outcomes in a child's future life. Previous studies reported association of skull deformities and abnormal language development, visualperception deficits, and delayed intellectual and motor development skills $(13,26,27)$. Therefore, children at school age usually require supportive education and speech therapy, physical therapy, and work education. These patients are also prone to astigmatism. Thus, it is common for these children to wear prescription glasses and they need to wear proper protective helmets to do some sport activities like snowboard, bicycle riding (28). Miller et al. reported that deformational infants with plagiocephaly consist of a high risk group for developmental difficulties at school age (29). Recently, a study using Bartley's developmental scale III on 6-month-old plagiocephaly infants showed that these babies are at high risk for delayed neurologic development (15). Steinbok et al. reported that $33 \%$ of infants with skull deformities needed educational support and $14 \%$ were located at special needs class (30). Thus, these patients need to be diagnosed early by neonatologists and general pediatricians not only to prevent aesthetic deformations but to prevent psychomotor developmental retardation, as well.

\section{CONCLUSION}

Recently, PSD prevalence has been on the rise. It is important that the pediatricians are able to evaluate the severity of the problem and establish an early diagnosis in these cases. Improvement rates of the asymmetry decrease with age due to decreasing skull enlargement rate by age. Early diagnosis and close follow-up are quite important so that the infants with this condition may benefit from conservative management.

Informed Consent: Informed consent was obtained from all of the families of individual participants included in the study

Compliance with Ethical Standards: This study is a retrospective data analiysis. However, All procedures performed in studies involving human participants were in accordance with the ethical standards of the institutional and/or national research committee and with the 1964 Helsinki declaration and its later amendments or comparable ethical standards.

Peer-review: Externally peer-reviewed.

Author Contributions: Concept - AO,SI,SÇ; Design - AO,SI,SÇ; Supervision - AO; Fundings $\mathrm{AO}$; Materials - AO; Data Collection and/or Processing - $\mathrm{AO}, \mathrm{SI}, \mathrm{SC}$; Analysis and/or Interpretation - AO,SI,SÇ; Literature Search - SI,SÇ; Writing Manuscript - SI,SÇ; Critical Review - AO

Conflict of Interest: No conflict of interest was declared by the authors.

Financial Disclosure: The authors declared that this study has received no financial support. 


\section{REFERENCES}

1. Clarren SK. Plagiocephaly and torticollis: etiology, natural history, and helmet treatment. J Pediatr 1981;98:92-95. [CrossRef]

2. Pollack IA, Losken HW, Fasick P. Diagnosis and management of posterior plagiocephaly. Pediatrics 1997;99:180-185. [CrossRef]

3. Kelly KM, Littlefield TR, Pomatto JK, Ripley CE, Beals SP, Joganic EF. Importance of early recognition and treatment of deformational plagiocephaly with orthotic cranioplasty. Cleft Palate-Craniofac J 1999;36:127-130. [CrossRef]

4. American Academy of Pediatrics, Task Force on Infant Positioning and SIDS. Positioning and sudden infant death syndrome. Pediatrics 1992;89:1120-1126.

5. American Academy of Pediatrics, Task Force on Infant Positioning and SIDS. Positioning and sudden infant death syndrome (SIDS): update. Pediatrics 1996;98:1216-1218.

6. Argenta LC, David LR, Wilson JA, Bell WO. An increase in infant cranial deformity with supine sleeping position. J Craniofac Surg 1996;7:5-11. [CrossRef]

7. Turk $\mathrm{AE}, \mathrm{McC}$ arthy JG, Thorne $\mathrm{CH}$, Wissoff JH. The "back to sleep campaign" and deformational plagiocephaly: is there a cause for concern? J Craniofac Surg 1996;7:12-18. [CrossRef]

8. Dörhage KWW, Beck-Broichsitter BE, von Grabe V, Sonntag A, Becker ST, Wiltfang J. Therapy efects of head orthoses in positional plagiocephaly. J Craniomaxillofac Surg 2016;44:1508-1514. [CrossRef]

9. Moghaddam MB, Brown TM, Clausen A, DaSilva T, Ho E, Forrest CR. Outcome analysis after helmet therapy using 3D photogrammetry in patients with deformational plagiocephaly: The role of root mean square. J Plast Reconstr Aesthet Surg 2014;67:159-165. [CrossRef]

10. Rowland K, Das N PURLs: Helmets for positional skull deformities: A good idea, or not? J Fam Pract 2015;64:44-46. [CrossRef]

11. Schulz M, Spors B, Haberl H, Thomale UW. Results of posterior cranial vault remodeling for plagiocephaly and brachycephaly by the meander technique. Childs Nerv Syst 2014;30:1517-1526. [CrossRef]

12. Morterson P, Steinbok P, Smith D. Deformational plagiocephaly and orthotic treatment: indications and limitations. Childs Nerv Syst 2012;28:1407-1412. [CrossRef]

13. Di Rocco C, Paternoster G, Caldarelli M, Massimi L, Tamburrini G. Anterior plagiocephaly: epidemiology, clinicalfindings, diagnosis, and classification. A review. Childs Nerv Syst 2012;28:1413-1422. [CrossRef]

14. Siatkowski RM, Fortney AC, Nazir SA, et al. Visual field defects in deformational posterior plagiocephaly. JAAPOS 2005;9:274-278. https://doi.org/10.1016/j.jaapos.2005.01.01

15. Speltz ML, Collett BR, Stott-Miller M, et al. Case control study of neurodevelopment in deformational plagiocephaly. Pediatrics 2010;125:e537-e542. [CrossRef]
16. Cakirer B, Hans MG, Graham G, Aylor J, Tishler PV, Redline S. The relationship between craniofacial morphology and obstructive sleep apnea in whites and African-Americans. Am J Respir Crit Care Med 2001;163:947-950. [CrossRef]

17. Purzycki A, Thompson E, Argenta L, David L. Incidence of otitis media in children with deformational plagiocephaly.J Craniofac Surg 2009;20:1407-1411. [CrossRef]

18. Kane AA, Lo L, Vannier MW, Marsh, JL. Mandibular dysmorphology in unicoronal synostosis and plagiocephaly without synostosis. Cleft Palate-Craniofac J 1996;33:418-423. [CrossRef]

19. Hutchison BL, Hutchison LA, Thompson JM, Mitchell EA Plagiocephaly and brachycephaly in the first two years of life: a prospective cohort study. Pediatrics 2004;114:970-980. [CrossRef]

20. American Academy of Pediatrics 2008. Back to sleep, tummy to play. Retrieved August 11, 2012, from: http://www.healthychildcare.org/ pdf/SIDStummytime.pdf

21. Shweikeh F, Nuno M, Danielpour M, Krieger MD, Drazin D. Positional plagiocephaly: an analysis of the literatüre on the effectiveness of current guidelines. Neurosurgical Focus 2013;35:E1. [CrossRef]

22. Farkas LG. Accuracy of anthropometric measurements: past, present, and future. Cleft Palate Craniofac J 1996;33:10-18. [CrossRef]

23. Mortenson PA, Steinbok P. Quantifying positional plagiocephaly: reliability and validity of anthropometric measurements. J Craniofac Surg 2006;17:413-419. [CrossRef]

24. Persing J, James $\mathrm{H}$, Swanson J, Kattwinkel J, American Academy of Pediatrics Committee on Practice and Ambulatory Medicine, Section on Plastic Surgery and Section on Neurological Surgery. Prevention and management of positional skull deformities in infants. American Academy of Pediatrics Committee on Practice and Ambulatory Medicine, Section on Plastic Surgery and Section on Neurological Surgery. Pediatrics 2003;112:199-202. [CrossRef]

25. Plank L, Giavedoni B, Lombardo J, Geil M, Reisner A. Comparison of infant head shape changes in deformational plagiocephaly following treatment with a cranial remolding orthosis using a noninvasive laser shape digitizer. J Craniofac Surg 2006;17:1084-1091. [CrossRef]

26. Kalra R, Walker ML. Posterior plagiocephaly. Childs Nerv Syst 2012;28:1389-1393. [CrossRef]

27. Collett B, Breiger D, King D, Cunningham M, Speltz $M$. Neurodevelopmental implications of "deformational" plagiocephaly. J Dev Behav Pediatr 2005;26:379-389. [CrossRef]

28. Binkiewicz-Glińska A, Mianowska A, Sokołów M, et al. Early Diagnosis and Treatment of Children with Skull Deformations. The Challenge of Modern Medicine. Dev Period Med 2016;20:289-295.

29. Miller RI, Clarren SK Long-term developmental outcomes in patients with deformational plagiocephaly. Pediatrics 2000;105:e26. [CrossRef]

30. Steinbok P, Lam D, Singh S, Mortenson PA, Singhal A. Long-term outcome of infants with positional occipital plagiocephaly. Childs Nerv Syst 2007;23:1275-1283. [CrossRef] 